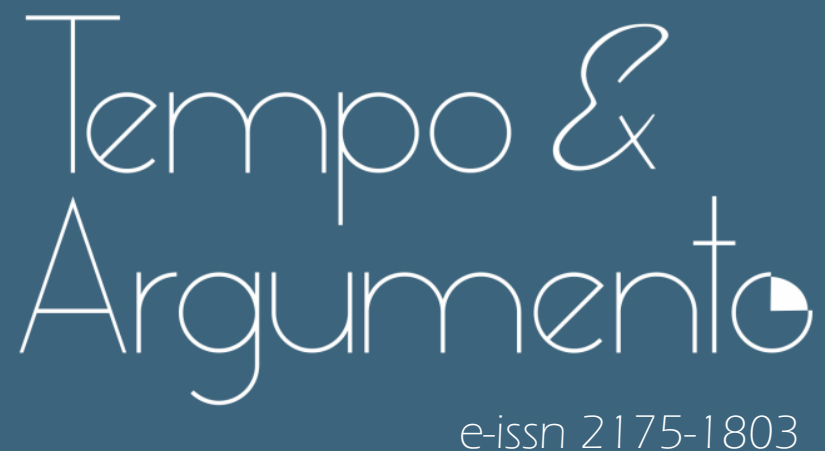

\title{
Entre a guerra, a doutrina e a tecnologia: um histórico da evolução doutrinária do exército dos Estados Unidos (1959-2017)
}

- Fernando da Silva Rodrigues

Doutor em História pela Universidade do Estado do Rio de Janeiro (UERJ).

Professor do Programa de Pós-Graduação em História da Universidade Salgado de

Oliveira (UNIVERSO).

Niterói, RJ - BRASIL

lattes.cnpq.br/9052163455007584

fernandoahex@gmail.com

(iD) orcid.org/0000-0003-3743-7970

- Augusto Wagner Menezes Teixeira Júnior

Doutor em Ciência Política pela Universidade Federal de Pernambuco (UFPE).

Professor permanente do Programa de Pós-Graduação em Ciência Política e

Relações Internacionais da Universidade Federal da Paraíba (UFPB).

João Pessoa, PB - BRASIL

lattes.cnpq.br/5020954657741658

augustoteixeirajr@gmail.com

(iD)

orcid.org/0000-0002-2569-1755

Para citar este artigo:

RODRIGUES, Fernando da Silva; TEIXEIRA JÚNIOR, Augusto W. M. Entre a guerra, a doutrina e a tecnologia: um histórico da evolução doutrinária do exército dos Estados Unidos (1959-2017). Tempo e Argumento, Florianópolis, v. 13, n. 32, e0110, jan./abr. 2021

doi) http://dx.doi.org/10.5965/2175180313322021 e0110 


\title{
Entre a guerra, a doutrina e a tecnologia: um histórico da evolução doutrinária do exército dos Estados Unidos (1959-2017)
}

\begin{abstract}
Resumo
Esta investigação analisa a história da evolução doutrinária do Exército dos Estados Unidos, no período que vai de 1959 a 2017. O artigo examina a dinâmica da mudança do paradigma dos conflitos e suas implicações para a transformação da Força Terrestre dos EUA. Com relação aos procedimentos metodológicos, a pesquisa apoiou-se no uso de documentos como o FM 3-24 Counterinsurgency (2006), da National Security Strategy (2017) e no Joint Operational Access Concept (2012). A partir de uma perspectiva histórica ampla e com base na literatura especializada, o escrutínio dos documentos contribuiu para a compreensão da evolução doutrinária do caso em estudo, no período que vai da Guerra do Vietnã à Guerra contra o Terror. De forma a aportar subsídios para a história do tempo presente, apresentamos como os processos avaliados apontam para a contemporaneidade da doutrina do U.S. Army. O estudo foi pautado nos argumentos teóricos da História Militar para os estudos da Guerra, a partir de múltiplas formas dimensionais, embasando-se em campos culturais, tecnológicos, sociais e também políticos.
\end{abstract}

Palavras-chave: Guerra. Doutrina. Política. Estados Unidos. Tecnologia.

\section{Between war, doctrine, and technology: a history of the doctrinal evolution of the United States Army (1959-2017)}

\begin{abstract}
This research examines the history of the doctrinal evolution of the United States Army in the period from 1959 to 2017. The article examines the dynamics of the changing conflict paradigm and its implications for the transformation of the U.S. Ground Force. Regarding methodological procedures, the research relied on the use of documents such as FM 3-24 Counterinsurgency (2006), the National Security Strategy (2017), and the Joint Operational Access Concept (2012). From a broad historical perspective and based on specialized literature, the scrutiny of the documents contributed to the understanding of the doctrinal evolution of the case under study, in the period from the Vietnam War to the War on Terror. In order to contribute to the history of the present time, we present how the processes assessed point to the contemporaneity of U.S. Army doctrine. The study was based on the theoretical arguments of Military History for the study of War, from multiple dimensional forms, based on cultural, technological, social, and also political fields.
\end{abstract}

Keywords: War. Doctrine. Politics. United States. Technology. 


\section{Introdução}

A partir do questionamento de como as forças armadas dos Estados Unidos (EUA), em particular o seu Exército, evoluem diante da mudança do paradigma dos conflitos, a investigação buscou analisar a evolução doutrinária da Força Terrestre do país supracitado. A pesquisa possui como recorte o contexto histórico que vai da Guerra do Vietnã até a chamada "Guerra ao Terror", esta última iniciada após os atentados ocorridos em território norte-americano em 11 de setembro de 2001. Essa nova ameaça passou a definir como eixo estratégico a guerra contra um inimigo preponderantemente não estatal, posicionado tanto dentro como fora das fronteiras de um Estado. Para além do objetivo proposto, e com base no balanço histórico objetivado, buscaremos também lançar luz sobre a atualização doutrinária recente, no contexto do retorno da competição entre grandes potências.

Desde a Primeira Guerra Mundial os grandes confrontos são percebidos como um princípio dinâmico da história de uma sociedade, o qual provoca mudanças paradigmáticas na historiografia (CORREIA, 2014). Com o desenvolvimento da grande guerra que se iniciou em 1914, é possível perceber a evolução da sua historiografia investigada por autores como Antoine Prost e Jay Winter, no livro Penser la Grande Guerre (WINTER; PROST, 2004). Essa realidade não é diferente do que acontecia no século XIX. Ao avaliarmos a guerra como um fenômeno político e social, nos damos conta da importância de se compreender os impactos causados pelos conflitos ao longo da história.

Nesse contexto, entendemos que há uma infinidade de possibilidades de estudo sobre a guerra, o que proporciona a interdisciplinaridade. Esta, tornada possível graças à revisão dos tradicionais modelos teórico-metodológicos no campo da História Militar. Essa mudança paradigmática é fruto de ruptura ocorrida nos anos 1990, que possibilitou a ampliação das categorias conceituais aplicadas às análises, levando ao surgimento de uma Nova História Militar (CASTRO; IZECKSOHN; KRAAY, 2004; PEDROSA, 2011). No Brasil, o movimento de

\footnotetext{
Também conhecida pela sigla GWOT (Global War on Terrorism), ou simplesmente Guerra ao Terror. A “Guerra Global ao Terrorismo" foi a denominação oficial do governo dos Estados Unidos (administração George W. Bush) para definir a série de operações, campanhas e guerras contra a ameaça do extremismo violento. Para mais informações, ver United States of America (2001).
} 
renovação coincide com o fim do regime militar em 1985, e com a implantação da Constituição Federal da República em 1988. Ambos os eventos contribuíram para o início da diminuição das tensões político-ideológicas existentes entre os pesquisadores civis e os militares (PEDROSA, 2011), em particular no que diz respeito à dificuldade de acesso aos documentos para estudos sobre as Forças Armadas (CASTRO; IZECKSOHN; KRAAY, 2004).

Para o estudo da guerra aplicado ao tempo presente, partimos do entendimento inicial sobre como a história e a historiografia se colocam em relação à discussão. No passado, muitas obras foram publicadas usando a abordagem da História Militar Tradicional, que se desenvolveu junto com a produção histórica positivista nos séculos XIX e XX. O modelo valorizava a Guerra como objeto do campo da história política, com base nos estudos sobre o Estado Nacional, a formação do território, a demarcação das fronteiras e as relações diplomáticas. Como coloca o historiador Pedrosa:

A História Militar tradicional tem sido o campo de "militares
historiadores". Em geral, tem pouca acuidade metodológica, pois
não resulta do trabalho de historiadores profissionais, mas de
aficionados. Tende, portanto, à grandiloqüência e à adjetivação
excessiva. É basicamente uma história descritiva e busca o ideal
de apresentar "os fatos como aconteceram". (PEDROSA, 2011, p. 8,
grifo nosso)

Com um trabalho bibliográfico histórico mais apurado, fica claro que os eventos militares já eram investigados cientificamente desde o século XIX. Essa modalidade de produção de conhecimento caracterizava-se como estudos metódicos, lineares e valorizados na medida em que legitimavam as ações políticas do Estado. Os dois principais modelos seguidos pela História Militar no século XIX foram elaborados pelo estrategista militar prussiano Carl Philipp Gottlieb Von Clausewitz ${ }^{2}$ e por Leopoldo Von Ranke. Enfatizando a relação entre

\footnotetext{
2 Não obstante Da Guerra (CLAUSEWITZ, 1984) apresentar um dos primeiros registros de estudo histórico sobre as Guerras Napoleônicas, o cerne de sua contribuição se dá em edificar uma teoria da guerra, centrada no entendimento de sua estratégia, natureza e característica. Dos oito livros que compõem Da Guerra, dois são essencialmente históricos, o livro 4 (O Engajamento) e 5 (Forças Militares). Focado no estudo da defesa (estratégica e tática), o livro 6 também apresenta um estudo sobre a Insurreição Popular à luz da experiência das Guerras Peninsulares. Para mais sobre esse tópico, ver os ensaios introdutórios de Peter Paret, Michael Howard e Bernard Brodie em Clausewitz (1984).
} 
guerra e política, colocando-a em contexto histórico e social, a obra Da Guerra (CLAUSEWITZ, 1984), principal tratado sobre o tema, analisa a guerra em sua essência, atrelada às sociedades modernas da época.

Como perspectiva alternativa, o modelo elaborado por Leopoldo Von Ranke, historicista prussiano cujo arcabouço teórico se baseava na História Narrativa linear, procurava apresentar os fatos históricos como eles realmente se passaram e tinha como princípio a objetividade e a neutralidade. A produção de Ranke baseava-se nos documentos diplomáticos oficiais para fazer a história do Estado e de suas relações exteriores, pois acreditava que as relações diplomáticas determinavam as iniciativas internas do Estado (REIS, 1996). Pelo paradigma tradicional, a história deveria ser construída baseada na descrição dos documentos, pois neles estava a verdadeira história.

A principal contribuição de Ranke foi a ênfase que deu à necessidade de fundamentar a escrita da história com base na leitura de documentos oficiais, produzidos pelo Estado e depositados em Arquivos Públicos. Esse modelo de fazer história levou a profissionalização da academia. Por outro lado, essa contribuição levou a história tradicional a se tornar uma história feita de cima, concentrando sua produção nos grandes feitos dos chefes de Estados, de generais e do alto clero.

A partir desse debate é importante destacar dois importantes objetos de estudos da história que foram trabalhados neste contexto e estão presentes nos estudos militares do século XIX e XX33: a História Batalha e a História Militar. A primeira, produzida a partir da busca de uma descrição precisa e de uma análise detalhada dos eventos militares propriamente ditos; a segunda, no contexto da História Política, segundo a qual todo o pensamento relacionado à guerra, no que diz respeito à destruição, à submissão, ao desarmamento do inimigo, à conquista de territórios e, também, às variadas batalhas, estariam intrinsecamente ligados às questões de poder (SANCHES, 2010; PEDROSA, 2011). Somadas às abordagens

\footnotetext{
${ }^{3}$ História Batalha, História Militar e História da Guerra referem-se à distintas abordagens de como o estudo da guerra se dá na História e nos Estudos Estratégicos. A partir da teoria da guerra de Clausewitz (1984), considera-se que a manifestação real do fenômeno da guerra pode ser decantada em níveis crescentes de complexidade, como por exemplo engajamentos/batalhas, campanhas e a guerra propriamente dita, desdobrando-se nos níveis político, estratégico e tático.
} 
da História Batalha e da História Militar, os Estudos Estratégicos incorporam a História, aqui caracterizada como História da Guerra (PASSOS, 2006; KEEGAN, 2006).

Se no século XIX, o modelo tradicional valorizava a guerra no contexto temático da História Política, com ênfase nos estudos sobre o Estado, na segunda metade do século XX e, no século XXI, novas pesquisas, com novas abordagens da área deram continuidade ao seu exame, mas de múltiplas formas dimensionais, embasando-se em campos culturais, econômicos, sociais e também políticos (SANCHES, 2010, p. 16). No século XX, para o filósofo e sociólogo francês Raymond Aron, "a guerra, enquanto ato social pressupõe a contraposição de vontades, isto é, pressupõe coletividades politicamente organizadas, cada uma das quais quer sobrepor-se às outras." (ARON, 1986, p. 69). Fortemente influenciado pela teoria da guerra clausewitziana, para Aron:

A guerra é um ato político, surge de uma situação política e resulta de uma razão política. Pertence por natureza ao diálogo puro, por tratar-se de um instrumento da política. O elemento passional interessa sobretudo ao povo; o elemento aleatório, ao exército e ao seu comandante; o elemento intelectual, ao governo; este último é decisivo e deve ordenar o conjunto. (ARON, 1986, p. 71)

Em contraposição ao estudo histórico de influência clausewitziana, entre as novas vertentes do estudo da guerra e da história militar, se destaca a contribuição culturalista de John Keegan (2006). Nas primeiras duas décadas do século XXI, notabilizadas por longas campanhas no Afeganistão e Iraque, a perspectiva culturalista da guerra ganhou terreno em detrimento da interpretação política do fenômeno bélico. Religião, cultura e sistemas de crenças não apenas foram incorporados às lentes analíticas sobre conflitos armados, como se tornaram desafios para a evolução doutrinária militar, em particular nos Estados Unidos.

Com relação aos procedimentos metodológicos, a pesquisa apoiou-se no uso de diversos documentos. A Estratégia Nacional de Segurança (National Security Strategy, 2017) e o Conceito Operacional Conjunto de Acesso (Joint Operational Access Concept, 2012), ajudaram a investigar a evolução doutrinária da Força Terrestre dos Estados Unidos da América (EUA), no período que vai da 
Guerra do Vietnã à "Guerra Global contra o Terrorismo"4. Sobre esta última, exploramos o Field Manual No. 3-24 / Fleet Marine Force Manual No. 3-24 (UNITED STATES OF AMERICA, 2006), Manual de Contrainsurgência cuja redação foi liderada pelos oficiais generais Petraeus e Mattis.

De forma complementar, analisamos documentos produzidos por militares americanos sobre a evolução doutrinária do país, entre os quais Benson (2012), Brown \& Perkins (2017). Para a compreensão do impacto da tecnologia na mudança e adaptação doutrinária do U.S. Army, apoiamo-nos no discurso sobre as Offset Strategies (estratégias de compensação) do ex-Secretário de Defesa dos Estados Unidos, Chuck Hagel (2014). Apoiados numa perspectiva histórica ampla, realizamos o balanço da evolução doutrinária da Força Terrestre apoiado também pela literatura especializada (FREEDMAN, 2003; ANDERSON, 2005; BACEVICH, 2008; KRETCHIK, 2011; BENSON, 2012; SLOAN, 2012; LOURENÇÃO e CORDEIRO, 2016; BROWN e PERKINGS, 2017).

Os documentos receberam tratamento qualitativo. Essa abordagem, realizada através da análise intratextual, pretendeu investigar a bibliografia, e os documentos produzidos pela Força Terrestre dos EUA, cujos registros escritos foram considerados como parte do discurso a ser compreendido e questionado quanto às intenções dos sujeitos históricos, ao papel dos militares e à evolução doutrinária. É necessário considerar que todo documento é portador de um discurso, uma construção, e não pode ser visto apenas como um registro que reproduz a verdade. Um texto não se dissocia de seu contexto de produção. Para analisar um registro escrito, a análise de um discurso deve contemplar simultaneamente três dimensões fundamentais: o intratexto, o intertexto e o contexto. O intratexto, ou o que está por trás do texto escrito, se refere aos aspectos internos do texto e implica na avaliação do texto como objeto de significação. O intertexto corresponde ao relacionamento de um texto com outros textos, para comprovar sua veracidade. O contexto representa à relação do texto com a realidade que o produziu e que o envolve (BARROS, 2002).

${ }^{4}$ Sobre essa expressão, ver nota de rodapé 1. 
Para Albuquerque Junior, discurso é a fala ou a oração construída para determinado público podendo ter sido escrito previamente ou falado de improviso (2009). Nesse sentido, quando utilizamos análise de discursos como metodologia de pesquisa, não devemos questionar apenas o que esses discursos nos dizem do passado, mas também identificar quais informações esses discursos revelam. Deve-se perguntar como esses discursos foram construídos, em que momento, a quem foi dirigido e em quais circunstâncias. Albuquerque Junior entende que os discursos são partes dos eventos históricos de uma determinada época tendo a função de tornar o passado e seus personagens vivos (2009). Em síntese, o contraponto entre a literatura especializada e o discurso oficial, mediados pela análise de discurso, se mostra fundamental para uma avaliação crítica dos documentos e análises produzidas por militares estadunidenses.

\section{A Guerra do Vietnã como base para mudanças doutrinárias: entre a} guerra convencional e a guerra assimétrica

Entre 1945 e 1962, a doutrina militar norte-americana é marcada por importantes mudanças, passando a ser publicada no Field Service Regulations Operations. No período, desenvolveu-se a doutrina de retaliação maciça ${ }^{5}$, adotada na administração do presidente Dwight Eisenhower (1953-1961). Com o advento do artefato nuclear, deu-se um prodigioso desenvolvimento de possibilidades doutrinárias sobre o seu emprego tático e estratégico, impulsionadas pela sua utilização militar em agosto de 1945 até o clímax da crise dos mísseis em 1962 (FREEDMAN, 2003). Os eventos de 6 e 9 de agosto de 1945, momentos derradeiros da Segunda Guerra Mundial, levaram as Forças Armadas dos Estados Unidos, a principal potência militar e econômica mundial, à condição de único detentor das armas nucleares. No entanto, o conflito favoreceu também a ascensão - entre 1946 e 1949 - da União das Repúblicas Socialistas Soviéticas (URSS), como potência militar adversária, principal antagonista geopolítico dos EUA.

\footnotetext{
${ }^{5}$ Doutrina referente ao emprego de armas nucleares no âmbito da deterrência nuclear. Sobre a evolução da estratégia nuclear, ver Freedman (2003).
} 
Com o sucesso no teste de armamento nuclear pela URSS em 1949, a evolução do pensamento estratégico e suas implicações doutrinárias tiveram com efeito nos Estados Unidos a priorização das armas nucleares em detrimento de sistemas convencionais. Percebendo-se em condição de assimetria de meios convencionais no teatro de operações ${ }^{6}$ Europeu diante da URSS, a administração Eisenhower desenvolveu a primeira Offset Strategy (Estratégia de Compensação) (HAGEL, 2014). Esta buscava apoiar-se na superioridade de suas capacidades nucleares como forma de balancear a insuficiência de meios convencionais disponíveis na Europa. Por essa razão, as diretrizes estratégicas e doutrinárias dos Estados Unidos ancoravam-se na centralidade das armas nucleares e de seus vetores de entrega (FREEDMAN, 2003).

Enquanto a orientação estratégica recaia na dissuasão nuclear, apoiada de forma complementar por meios convencionais orientados para a guerra de alta intensidade, emergia no panorama estratégico a centralidade de desafios irregulares, como guerrilhas e insurgências. O período entre 1959 e 1973 marcou o momento em que os EUA aprofundaram e encerraram a sua participação na Guerra do Vietnã. O deslocamento em massa de tropas de combate começou em 1965, após o incidente do Golfo de Tonkin. As forças americanas conquistaram território e controlavam o campo de batalha tradicional; no entanto, sofreram mais baixas na luta contra a guerrilha Vietcong do que contra forças regulares do Exército Norte vietnamita. Taticamente, os EUA não perderam nenhuma grande batalha. No entanto, apesar da sua superioridade tecnológica e logística, os americanos não conseguiram sobrepujar seus adversários nos níveis estratégicos e político (ANDERSON, 2005). Fundamentalmente, os EUA falharam em interpretar corretamente a guerra. Sendo incapaz de determinar corretamente os centros de gravidade do inimigo ${ }^{7}$, falhando por essa razão em conectar o sucesso militar no nível tático à resultados estratégicos e vitória política na guerra.

\footnotetext{
${ }^{6}$ Teatro de operações refere-se a uma delimitação do ambiente físico da guerra. Decantando-a nos níveis político, estratégico e tático, o nível do teatro situa-se entre o tático e o nível estratégico.

Para Clausewitz (1984), o "Centro de Gravidade" representa o ponto central do poder do inimigo e a sua correta identificação permitiria atacar capacidades críticas de combate (física e moral), contribuindo para a derrota do oponente.
} 
Após o fim da Guerra do Vietnã, os EUA iniciaram a revisão de sua orientação estratégica na Guerra Fria. Entre os legados da "Síndrome do Vietnã", destaca-se a preferência por evitar a guerra irregular, reiterando a preferência estratégica e doutrinária pela guerra convencional, lastreada na superioridade tecnológica e de alta intensidade. Apenas na segunda metade dos anos 2000 é que a guerra irregular retomaria espaço de destaque para além de unidades de forças especiais e comandos. Como exemplo, em resposta à violência sectária no Iraque, os generais David Petraeus (U.S. Army) e o Marine Lt. Gen. James N. Mattis (U.S. Marine Corps) lideraram a redação do manual de contrainsurgência intitulado U.S. Army Field Manual 3-24 "Counterinsurgency" (UNITED STATES OF AMERICA, 2006). Aplicado durante o "Surge" de tropas americanas no Iraque em 2007, a experiência foi vista como um sucesso e resposta ao desafio de segurança da insurgência iraquiana. Em adição, o retorno à doutrina de contrainsurgência demonstrava - embora com problemas - a flexibilidade doutrinária das forças americanas para o combate contra insurgências (BACEVICH, 2008).

Desde o término da Segunda Guerra Mundial, tendo a URSS como principal adversário, os EUA entendiam que a Europa Ocidental e o Extremo Oriente eram as áreas de maior risco de confronto militar. Por isso, seguindo orientações geopolíticas que centravam esforços nas duas franjas da Eurásia (KAPLAN, 2013), a grande concentração de forças nas regiões tornava possível tanto a contenção geoestratégica de seus oponentes (URSS e China), como a projeção de poder militar para essas áreas. No entanto, o número de regiões em tensão aumentou na proporção que ocorria o processo de descolonização na África, na Ásia e no Oriente Médio, que embora mesclassem objetivos ligados à autodeterminação dos povos e de libertação nacional, também ficavam sujeitas à influência doutrinária da URSS.

Ainda sob os efeitos do resultado da Guerra do Vietnã e da ebulição política no então Terceiro Mundo entre os anos 1960 e 1970, a década de 1980 foi marcada pela reorganização da estrutura e mudança doutrinária das forças armadas dos EUA (ANDERSON, 2005). A evolução doutrinária no período foi fortemente influenciada por mudanças relacionadas à profissionalização do 
efetivo, à criação de uma força formada por voluntários (fim da conscrição draft), aos avanços na tecnologia militar e no treinamento das tropas, ao surgimento das Forças Epeciais Delta do Exército e à reforma do Departamento de Defesa (LOURENÇÃO; CORDEIRO, 2016). No âmbito da Defesa, a elaboração da doutrina Weinberger coroou esse processo de reformulação, o qual viria a impactar seriamente a Força Terrestre. Discorreremos sobre essas mudanças nos parágrafos a seguir.

A Guerra do Vietnã foi o último conflito em que a conscrição obrigatória foi adotada nos Estados Unidos. O exército passou a ser uma força completamente voluntária, dando mais enfase ao treinamento e ao desenvolvimento tecnológico, quebrando o paradigma das tensões sociais de críticas ao modelo de recrutamento e a pressão midiática do horror à guerra. 0 objetivo era diminuir a pressão social e modificar a forma de combater. Entretanto, o inimigo ainda era percebido como uma entidade política regular, ou seja, uma ameaça estatal.

Espelhando a mudança doutrinária em curso, no campo tecnológico, o Exército procurou desenvolver carros de combate menores, mais leves e rápidos. Como ocorrera no início da Guerra Fria, entre o final dos anos 1970 e início da década de 1980, o governo americano iniciou a Second Offset Strategy (Segunda Estratégia de Compensação) (HAGEL, 2014). Buscando manter a superioridade tecnológica dos Estados Unidos, pilar essencial para a sua condição de primazia global, a segunda versão da estratégia de compensação centrou esforços no desenvolvimento e produção de sistemas que estabeleceu a produção de capacidades de invisibilidade ao radar (Stealth), capacidade de ataque em longas distâncias (Long-Range Strike Capabilities) ligados às munições guiadas de precisão (precision-guided munitions - PGM) e sistemas e sensores para atividades de inteligência, vigilância e reconhecimento (Intelligence, Surveillance and Reconnaissance - ISR). Com relação à doutrina, foi estabelecido ainda, em 1o de julho de 1973, o Comando de Treinamento e Doutrina do Exército dos EUA ( $U$. S. Army Training and Doctrine Command / US TRADOC), encarregado de supervisionar o treinamento da tropa terrestre e o desenvolvimento da doutrina operacional. 
Segundo a doutrina Weinberger, os EUA deveriam estar preparados, em qualquer momento (Defesa Ativa ${ }^{8}$ ), para atuar contra ameaças de diferentes intensidades, como atos terroristas isolados, ações de guerrilha e confronto militar tradicional. Para isso, a relação entre objetivos e desenho de força tamanho, composição e disposição - deveriam ser continuamente reajustadas.

Além dos vetores de mudança doutrinária no âmbito do Departamento de Defesa, a política internacional entre os anos 1970 e 1980 foi um expressivo contributo para a adaptação da Força Terrestre a uma época de transição. Em 1979, o equilíbrio regional do Oriente Médio foi comprometido pela Revolução Iraniana e pela invasão soviética ao Afeganistão. A deposição de Mohammad Reza Pahlevi, monarca favorável ao Ocidente, causaria efeitos prolongados tanto na segurança regional, como na evolução doutrinária das forças armadas dos EUA.

Em 1980, foi criada uma força tarefa de Forças Integradas de Deslocamento Rápido (Rapid Deployement Joint Task Force / RDJTF). Em 1983, o RDJTF se transformou no Comando Unificado de Combate (Central Command / CENTOM) para atuar na África, no Sudoeste da Ásia e no Oriente Médio. No entanto, foi a necessidade de ação rápida dos EUA na América Central (Panamá - 1989), na região do Pacífico (Filipinas - 1990) e Europa (Guerra Civil da República Socialista Federativa da lugoslávia - 1991/2001), que transformou as forças de deslocamento rápido em um conceito de integração de forças (Exército, Fuzileiros Navais, Força Aérea e Marinha) com capacidades específicas e uma importante atribuição funcional (PROENÇA JÚNIOR; DUARTE, 2003).

A partir de 1986 ocorreu importante mudança no Departamento de Defesa dos EUA, com a implantação da Lei Goldwater-Nichols de Reorganização da Defesa (Goldwater-Nichols Defense Reorganization Act), de 1986, acrescida da Emenda Cohen-Nunn (Cohen-Nunn Amendment), de 1987 (LOCHER III; NUNN, 2004). Esse conjunto de mudanças legais e institucionais constituiriam o eixo central da reforma do setor de defesa nos Estados Unidos, contribuindo sobremaneira para a estruturação de uma força conjunta, flexível e interoperável.

\footnotetext{
\& Segundo o DOD Dictionary of Military and Associated Terms, Defesa Ativa consiste no "emprego de ação ofensiva limitada e contra-ataques para negar uma área contestada ou posição para o inimigo." (UNITED STATES OF AMERICA, 2021, p. 7).
} 
A chamada "Lei Goldwater-Nichols" criou o Comando Unificado de Combate (Unified Combatant Command), modificando a estrutura organizacional e unificando o comando dos Departamentos das Forças Armadas. Pela lei, o controle das Forças Armadas passou a seguir a cadeia de comando do presidente ao secretário de defesa diretamente para o Comando de Combate Unificado, que tem o comando de todas as unidades militares.

Os secretários dos departamentos militares passam a ter a responsabilidade de organizar, treinar e equipar sua tropa. Esses dispositivos legais significaram um avanço rumo ao fim da independência das Forças Armadas, fortalecendo o papel do Estado Maior Conjunto (Joint Chiefs of Staff). A emenda Cohen-Nunn reorganizou as Forças de Operações Especiais, reunindoas sob o Special Operation Command (SOCOM), que ficariam subordinadas aos comandantes das regiões somente quando operassem no território respectivo desse comando. O SOCOM controlaria o orçamento, o treinamento e a doutrina de todas as Forças de Operações Especiais.

Nesse contexto, ocorreu em 1989 a reunificação da Alemanha, e com o fim da União das Repúblicas Socialistas Soviéticas, em 1991, a Guerra Fria chegou ao fim. Parecia que os EUA poderiam usufruir de um período de paz que resultasse na redução do orçamento da defesa e na redução das Forças Armadas. No entanto, as tensões mundiais continuaram, agora com a possibilidade de diferentes frentes de combate contra atores estatais e não estatais. Antes, inclusive da dissolução e colapso da União Soviética, entre 1990 e 1991, ocorreu a Primeira Guerra do Golfo. Na ocasião da exarcebação de controvérsias sobre o preço do petróleo, o Iraque invadiu o Kuwait. Prontamente, a comunidade internacional sob a figura do Conselho de Segurança das Nações Unidas autorizou a formação de uma Coalizão para expulsar as tropas iraquianas do país vizinho, restaurando assim o status quo ante.

Após a invasão do Kuwait pelo Iraque em 1990, foi lançada em 1991 a Operação Tempestade do Deserto (Primeira Guerra do Golfo). Com um quantitativo de tropa somando 500.000 homens, a Coalizão foi liderada pelos Estados Unidos. Com a tropas dos Estados Unidos na vanguarda, os aliados expulsaram os iraquianos do Kuwait. Considerada como a melhor representação 
da doutrina de Batalha Aeroterrestre, ou Airland Battle (BENSON, 2012), a campanha terminou com as tropas aliadas vencendo o exército do Iraque em apenas 100 horas. Sofrendo pouquíssimas baixas, o exército dos Estados Unidos mostrou que havia conseguido se reinventar de forma muito bem sucedida. Novos armamentos, tecnologia avançada e melhor treinamento aos soldados se mostrou muito eficiente. Conforme demonstrou Biddle (2004), doutrina superior e a incorporação do que chamou de "modern system" contribuíram decisivamente para cristalizar a superioridade militar inconteste dos Estados Unidos em termos convencionais.

Tendo os debates sobre Revolução dos Assuntos Militares (RAM) como pano de fundo (KRAUTHAMMER, 1990), e o evento paradigmático da Primeira Guerra do Golfo, os Estados Unidos emergiram como uma superpotência militarmente hegemônica, que lideraria uma nova ordem mundial baseada na democracia liberal (OWENS, 1996; HUNTINGTON, 1999). Sem importantes adversários diretos e detentor de uma força militar sem concorrentes, os Estados Unidos focaram em atores estatais menores e na cooperação como doutrina de emprego.

No período, Colin Powell, chefe do Estado Maior Conjunto das Forças Armadas dos EUA (1989-1993), definiu uma nova estratégia militar (Doutrina Powell), alegando que a instabilidade política mundial tende a crescer após a queda de grandes potências. A nova estratégia dos EUA seria dirigida às incertezas regionais, em substituição à guerra global contra a ex-URSS, devendo suas forças armadas ter capacidade de conduzir um grande número de missões e lidar com várias ameaças simultâneas. Pela Doutrina Powell, a ação militar só deveria ser utilizada quando recebesse apoio da opinião pública.

No governo Bill Clinton (1993-2001), com os novos paradigmas das incertezas regionais, a formulação da segurança nacional priorizou temas como direitos humanos e relações comerciais. Com o objetivo de repensar aspectos da política militar dos Estados Unidos, o secretário de Defesa Leslie Aspin começou um processo chamado Bottom-Up Review (BUR), ou revisão de baixo para cima. $O$ resultado da revisão foram duas conclusões: primeiro, que o principal interesse dos EUA era a expansão mundial da prosperidade econômica; para tanto, as 
Forças Armadas deveriam atuar como mantenedoras da estabilidade global; e, segundo, para continuar projetando poder em diversos pontos do globo, as Forças Armadas deveriam se tornar mais leves, rápidas e ágeis, apoiadas por tecnologia de ponta (SLOAN, 2012).

A revisão foi aprovada pela Força Aérea e pelo Comando de Operações Especiais, que perceberam a oportunidade de receber maior aporte tecnológico. O Exército, por sua vez, entendeu como uma fragilidade de sua importância no novo cenário da guerra. Neste novo modelo, ao invés da artilharia e dos carros de combates, o poder de fogo pesado viria da aviação. No lugar da primazia do exército convencional, as forças militares de combate terrestre seriam centradas em Forças de Operações Especiais, as quais seriam mais leves e rápidas, além de usarem tecnologias mais sofisticadas. Diante da necessidade de suprir o contigente da tropa terrestre convencional em atuação, se previa o recrutamento de forças locais treinadas pelas Forças Especiais do Exército.

Como resultado da revisão, os EUA reduziram suas Forças Armadas, mantendo a capacidade de conduzir duas frentes de guerras. Esse cenário tornou-se realidade em 2001 e 2003. A partir de outubro de 2001, a Guerra do Afeganistão (Operation Enduring Freedom) deu-se com o objetivo de atacar a AlQaeda, responsabilizada pelo atentado terrorista contra os EUA, e remover o regime Talibã naquele país. Em março de 2003, iniciou-se a Segunda Guerra do Golfo (Operation Iraq Freedom), objetivando a destituição do governo vigente e da destruição de alegadas armas de destruição em massa. Como se verá na seção a seguir, os conflitos supracitados foram cruciais para expressivas mudanças doutrinárias nas forças armadas dos EUA, com claros impactos para o U.S. Army.

Da Guerra ao Terror ao retorno da competição entre grandes potências

O combate às novas ameaças evidenciadas após os atentados terroristas de 11 de setembro de 2001 levou à mudança na forma de combater o inimigo. Não obstante a guerra irregular e o uso de forças irregulares e regulares para esses fins seja corrente ao longo da história (VISACRO, 2009), a resposta 
americana ao desafio estratégico da Al-Qaeda elevou a guerra irregular a outro patamar. Pelo novo modelo de enfrentamento, não havia a necessidade de se aplicar o uso das grandes unidades de combate com ações clássicas. O enfrentamento deveria ser baseado em pequenos grupos de operações especiais. O que ficou claro é que, na guerra no início do século XXI, as Forças Armadas passam a combater, prioritariamente, oponentes não estatais, tais como Al-Qaeda, o Hamas, o Hezbollah, as Forças Armadas Revolucionárias da Colômbia (FARC), o Estado Islâmico, entre outros. O combate contra irregulares torna-se inclusive mais complexo dado que guerrilheiros, terroristas e insurgentes não seguem os regramentos do direito internacional dos conflitos armados, e apesar de se apresentarem como soldados, seus combatentes estão inseridos entre a população civil.

Após os atentados de 11 de setembro de 2001, os EUA e seus aliados da Organização do Tratado do Atlântico Norte (OTAN) invadiram o Afeganistão e derrubaram o regime Talibã que governava o país, alegando que este dava apoio ao terrorismo internacional. Conforme se notabilizou ao longo da Guerra do Afeganistão, os ataques terroristas de 11 de setembro de 2001 consagraram o uso do modelo atual de confltitos entre uma força estatal contra grupos insurgentes não convencionais, conhecido como low-intensity conflicts ou small wars, que podem ser tão violentos quanto uma guerra convencional. Um ponto inovador nas novas ações militares contra o Afeganistão e o Iraque foi o papel de liderança dado à Central de Inteligência Americana (CIA), que possuía consideráveis conhecimentos das regiões, das culturas e dos grupos étnicos que poderiam cooperar com as tropas americanas. Outro ponto novo foi o uso de força local nativa, junto com Forças de Operações Especiais, equipes da CIA e apoio aéreo dado pelo US Central Command (USCENTCOM) dessa região.

A ação militar no Afeganistão resultou no crescimento da importância do socom, que na gestão do secretário Donald Rumsfield foi expandido e ganhou

\footnotetext{
9 Esse Comando Central é responsável por defender e promover os interesses dos EUA em vinte países no Oriente Médio, incluindo o Egito, Ásia Central (Afeganistão e Iraque), Sul da Ásia e nos canais estratégicos que os cercam. É um Comando Unificado de Combate do Departamento de Defesa dos EUA. Foi criado em 1983, para substituir permanentemente as funções da Força Tarefa Conjunta de Deslocamento Rápido criada em março de 1980, durante a crise dos reféns no Irã e a invasão soviética do Afeganistão. Ver Cordesman,1998.
} 
autonomia de comando regional, com mais autoridade para planejar e lutar a guerra contra o terror. O Departamento de Defesa dos EUA definiu que unidades menores compostas por pessoal altamente treinado seriam mais eficazes do que forças convencionais. Nesse momento, consolidou-se a tendência de diminuir o tamanho das Forças Armadas dos EUA, tornando-as mais leves e ágeis. Essa tendência intensificou-se na gestão do secretário de Defesa, Robert Gates (20062011), que continuou a priorizar o emprego das Forças de Operações Especiais, reduzindo a participação das forças convencionais.

A transformação ocorrida no exército dos EUA, na forma da condução da guerra, depois do ataque terrorista de 11 de setembro de 2001, resultou na reorganização da defesa, amparada na introdução de novas tecnologias e sistemas de armas. O foco na atuação de grupos de operações especiais, de tropas mais enxutas e no aprofundamento da profissionalização militar levou à incorporação de novas táticas de guerra. Essas novas táticas têm corroborado a vitória militar nas batalhas, mas não tem contribuído para a conquista psicossocial do inimigo, o que vai na contramão do atual pensamento estratégico norte-americano.

Nesse contexto, as campanhas após o ataque terrorista aos Estados Unidos da América significam vitórias no campo militar, mas são incompatíveis com a conquista de corações e mentes num processo de paz mais duradoura, que devem ser realizadas com atuação humanitária com os povos nativos nas áreas de operações, com o objetivo de obter vitórias morais. A não execução dessa parte do processo tem causado mal-estar junto à população local, e aumentado o sentimento antiamericano. Em outros termos, apesar da assimetria militar ao seu favor, os Estados Unidos continuam exibindo deficiências em sua estratégia (ends, ways and means), tal como na identificação correta dos centros de gravidade de seus inimigos (LOURENÇÃO; CORDEIRO, 2016).

Como eco da resposta americana ao atentado de 2001, entretanto mais relacionada à ameaça de armas de destruição em massa, a invasão do Iraque em 2003 se relaciona intimamente com a conhecida Doutrina Rumsfeld. Na gestão do Secretário de Defesa, Donald Rumsfeld (2001-2006), ocorreu a introdução do conceito de Shock and Awe (choque e pavor), revelando a evolução tática do 
conceito Hammer and Anvil (martelo e bigorna ${ }^{10}$ ), que consolidou a tendência das denominadas operações cirúrgicas, de alta precisão. Para o conceito Shock and Awe, ou também conhecido como Rapid Dominance, um ataque deve ser tão avassalador fisicamente, que o inimigo se sinta psicologicamente vulnerável e intimidado para tentar qualquer resistência (SLOAN, 2012). A estratégia de Rumsfield definia que as Forças Armadas, além da responsabilidade de defesa do território dos EUA e do de seus aliados contra um conflito principal, deveriam estar capacitadas a conduzir ao mesmo tempo outras operações em diferentes cenários.

Para Donald Rumsfeld, a nova doutrina militar dos EUA deveria ter o poder de satisfazer quatro objetivos militares e políticos: vencer dois grandes agressores simultaneamente, ter possibilidade de conduzir uma ampla contraofensiva, e ocupar a capital de um inimigo para nela instalar um novo regime. No contexto acima, era traçada a essência da nova era da hegemonia militar dos EUA, colocando no mesmo campo inimigo, organizações terroristas e países que apoiavam essa causa. As novas ameaças incluiam o terrorismo, ataques espaciais, ciberataques contra o sistema de comunicações, ataques com mísseis de cruzeiros, mísseis balísticos, armamento químico e armas biológicas.

As mudanças realizadas por Donald Rumsfeld não significaram apenas a criação de uma doutrina de emprego da força militar. Elas resultaram também numa revolução nos assuntos militares, concebida para responder a qualquer tipo de conflito. A mudança está ligada ao uso de novas tecnologias referentes à precisão dos tiros de longo alcance (projeto de defesa antimísseis), à informação permanente sobre as forças presentes e busca de alvos eventuais. No período foi construído o conceito de controle estratégico, que consistia estar em condições de identificar a situação do adversário, e com capacidade para reduzir o seu pontencial pela destruição de sua capacidade militar, industrial e política. Esse conceito não implicava a ocupação do território do inimigo, pelo menos na

\footnotetext{
10 A tática do martelo e bigorna remonta à época das campanhas militares de Alexandre da Macedônia, em que uma parte da tropa segura o inimigo, fazendo o papel de bigorna, enquanto a outra parte golpeia, fazendo o papel de martelo. No caso dos EUA, as tropas terrestres eram a bigorna e o poder aéreo, o martelo.
} 
primeira fase do conflito, e a ação terrestre deveria ficar restrita aos objetivos determinados pelo poder político estatal.

É notável que, não obstante a superioridade tecnológica dos Estados Unidos, ambos os conflitos foram marcados por curtas campanhas de guerra convencional e longas fases de guerra irregular, em que a assimetria constrangeu e influenciou o repertório tático e estratégico dos beligerantes. Nesse contexto, para adaptar-se aos novos cenários da guerra moderna, o Pentágono lançou o chamado Programa FCS (Future Combat Systems). O FCS foi o principal programa de modernização do Exército dos EUA entre 2003 e o início de 2009, com novas armas, táticas e melhor formação para os soldados, na luta contrainsurgência. O programa foi concebido para criar novas brigadas equipadas com veículos tripulados e não tripulados, ligados por uma rede de campo de batalha rápida e flexível.

Conforme demonstrado previamente, apesar da flexibilidade estratégica e tática das forças armadas dos Estados Unidos para se adequar a distintos perfis de oponentes, existe a preferência por travar guerras convencionais. Nesse sentido, os dois principais conflitos da primeira década do século XXI são representativos da relação entre preferências doutrinárias e os dilemas presentes na realidade do espaço e campo de batalha. Na fase inicial da Guerra do Afeganistão, em 2001, agindo em coalizão com as forças da Aliança do Norte, as forças americanas lograram posicionar pequenos contigentes de tropa no país. Estas ampararam substantivamente as manobras ofensivas de seus aliados em solo, apoiados majoritariamente por um poder aéreo avassalador (SLOAN, 2012). Elementos de forças de operações especiais e comandos do United States Special Operations Command (USSOCOM), articulados aos meios aéreos desdobrados na área de operações, permitiram imprimir uma dinâmica regular de conflito naquele momento da guerra afegã.

Por sua vez, em 2003, apoiando-se na doutrina do Shock and Awe (Choque e Pavor), a campanha convencional na primeira fase da guerra do Iraque foi um sucesso. Em poucas semanas, forças americanas e de sua pequena coalizão chegaram a Bagdad e derrubaram o regime de Saddan Hussein. Mais uma vez, uma campanha de bombardeio de grandes proporções, orientada a 
promover a paralisia estratégica do inimigo, acompanhada de um rápido avanço até a capital (centro de gravidade daquela fase de operações), quando os americanos imprimiram a lógica convencional de conflito à sua condução estratégica.

Conforme aprofundado na seção anterior, ambas as guerras desembocaram em longas guerras irregulares, fortemente orientadas à luta contra insurgências urbanas e rurais e a penosas missões de estabilização e reconstrução nacional. Esse período criou uma contradição relevante: enquanto as forças armadas dos Estados Unidos se empenhavam em operações militares decorrentes da Global War on Terror (GWOT), emergiam no horizonte desafios estratégico-militares convencionais que mais uma vez salientavam a primazia do preparo para a guerra convencional de alta intensidade. No decorrer do início da segunda década do século XXI, ao lado do extreminismo islâmico ainda percebido como ameaça existencial, grandes potências (China e Rússia) e potências regionais (Coreia do Norte e Irã) faziam ressurgir ameaças estatais de peso. Essa perspectiva é ressaltada na administração Obama ao promover o chamado "Rebalance to Asia", visando a China, tal como se cristaliza na Estratégia de Segurança Nacional dos Estados Unidos do governo Trump (UNITED STATES OF AMERICA, 2017).

Entre a segunda administração Obama e o governo Trump, ocorreram importantes mudanças no campo tecnológico e doutrinário nas forças armadas dos Estados Unidos. Como ocorreu em momentos anteriores (anos 1950 e 1970), em que Washington percebia-se ameaçada por seus contendores estratégicos. Em 2014 foi lançada a Third Offset Strategy (HAGEL, 2014), embora os Estados Unidos continuassem como a principal potência militar global, o governo Obama partia da percepção que a sua condição de superioridade estava sendo erodida por seus concorrentes. A difusão do acesso a sistemas de mísseis e de defesa antiaérea, o desenvolvimento da guerra cibernética e de medidas de guerra eletrônica contribuíam para o maior desafio operacional às forças americanas: a possibilidade de êxito inimigo em ações de antiacesso e de negação de área, o que veio a ser conhecido pelo acrônimo inglês de A2/AD (Antiaccess and Area Denial) (ELLMAN; SAMP; COLL, 2017). 
No campo doutrinário, importantes reações vieram a surgir. Enquanto os desafios da primeira década do século XXI urgiam por respostas às ameças irregulares, levando ao surgimento de doutrinas como a Full Spectrum Operations e Unified Land Operations (BENSON, 2012), o Joint Chiefs of Staff publicou em 2012 o Joint Operational Access Concept (UNITED STATES OF AMERICA, 2012). Fortemente orientado para guerra e operações convencionas, o JOAC expunha um conceito operativo conjunto em resposta aos desafios de A2/AD então desenvolvidos por parte da Rússia, da China, e da Coreia do Norte. $\mathrm{Na}$ atualidade, em resposta ao A2/AD, as forças armadas dos Estados Unidos desenvolvem e internalizam a doutrina Multi-Domain Operations (BROWN; PERKINS, 2017).

\section{Considerações finais}

A partir do diálogo com distintas perspectivas acerca da questão militar, como a História Batalha, História Militar e a História da Guerra, o presente artigo buscou contribuir para a compreensão de como a Força Terrestre da principal potência militar do planeta chegou a sua postura estratégica presente. Para tal objetivo, o texto analisou a evolução doutrinária do U.S. Army, à luz das mudanças no paradigma dos conflitos e de suas repercussões em distintos níveis de doutrina (presidencial, defesa e militar). Conforme foi possível constatar, o estudo da evolução doutrinária do poder militar permitiu compreender como os Estados Unidos se preparam e aplicam o instrumento bélico para a consecução de seus objetivos políticos. Dessa forma, o estudo da doutrina se mostrou como uma forma de contribuir para a interpretação acerca dos dilemas e escolhas estratégicas tanto ao longo da história, como no tempo presente.

De forma mais detida, a partir da investigação realizada em parte da documentação produzida pelo Exército dos Estados Unidos, que revelou a história da evolução doutrinária da Força Terrestre, no período de 1959 a 2017 , podemos refletir que, as transformações ocorridas na forma de conduzir os conflitos, principalmente a partir do ataque do 11 de setembro de 2001 resultaram na reorganização da Doutrina Militar, fortemente amparada na introdução de novas tecnologias e sistemas de armas. O estudo da National Security Strategy 
(2017) e do Joint Operational Access Concept (2012) foram fundamentais para nossa reflexão.

A investigação revela que, não obstante a relevância da mudança no paradigma dos conflitos e a evolução tecnológica, a evolução na doutrina fundamentou um papel significativo na adaptação do Exército ao longo de sua história - embora nem sempre a seu favor, pois muitas vezes não conseguiu prever com precisão a natureza da próxima guerra e continua na atualidade a ser travada em um debate entre defensores da guerra convencional e aqueles que defendem abordagens de contrainsurgência. A doutrina continua a ser a base da instrução no sistema de ensino do Exército, garantindo que todos os oficiais e soldados alistados compartilhem uma estrutura intelectual comum.

\section{Referências}

ALBUQUERQUE JÚNIOR, Durval Muniz. A dimensão retórica da historiografia. In: PINSKY, Carla Bassanezi (org.). O historiador e suas fontes. São Paulo: Contexto, 2009.

ALMEIDA, Rodrigo Torres de. Construção e expansão do complexo industrialmilitar norte-americano: um passo em direção ao poder global. 2013.

Dissertação (Mestrado em Economia). Rio de Janeiro: Instituto de Economia da UFRJ, 2013.

ANDERSON, David L. The Vietnam War. New York: Palgrave Macmillan, 2005.

ARON, Raymond. Paz e guerra entre as nações. 2. ed. Brasília: Editora Universidade de Brasília, 1986.

BACEVICH, Andrew J. The petraeus doctrine. In: THE ATLANTIC. [S.l.], Oct. 2008. Disponivel em: https://www.theatlantic.com/magazine/archive/2008/10/thepetraeus-doctrine/306964/. Acesso em: 27 out. 2020.

BARROS, José D’Assunção. O campo histórico: as especialidades e abordagem da História. 1. ed. Rio de Janeiro: editora Cela, 2002.

BENSON, Bill. Unified land operations: the evolution of army doctrine for success in the 21st Century. Military Review, [s.l.], p. 47-57, Mar./Apr. 2012. 
BIDDLE, Stephen. Military Power: explaining victory and defeat in modern battle. Princeton: Princeton University Press, 2004.

BROWN, Robert B.; PERKINS, David G. Multi-domain battle: tonight, tomorrow, and the future fight. War on the rocks, [s.l.], 18 Aug. 2017. Disponível em: https://warontherocks.com/2017/08/multi-domain-battle-tonight-tomorrowand-the-future-

fight/\#: :text=Multi\%2DDomain\%20Battle\%20Tomorrow,as\%20peers\%20on\%20t he\%20battlefield. Acesso em: 28 abr. 2021.

CASTRO, Celso; IZECKSOHN, Vitor; KRAAY, Hendrik (org.). Nova história militar brasileira. Rio de Janeiro: FGV: Bom Texto, 2004.

CLAUSEWITZ, Carl Von. On War. Princeton: Princeton University Press, 1984.

CORDESMAN, Anthony. USCENTCOM mission and history. [S.l.]: Center for Strategic and Internacional Studies, Aug. 1998. Disponível em: https://csisprod.s3.amazonaws.com/s3fs-

public/legacy_files/files/media/csis/pubs/uscentcom3\%5B1\%5D.pdf. Acesso em: 28 abr. 2021.

CORREIA, Sílvia Adriana Barbosa. Cem anos de historiografia da Primeira Guerra Mundial: entre história transnacional e política nacional. Topoi, Rio de Janeiro, v. 15, n. 29, p. 650-673, jul./dez., 2014. Disponível em: https://www.scielo.br/pdf/topoi/v15n29/1518-3319-topoi-15-29-00650.pdf. Acesso em: 31 out. 2020.

FREEDMAN, Lawrence. As duas primeiras gerações de estrategistas nucleares. In: PARET, Peter (org.). Construtores da estratégia moderna. Rio de Janeiro: Biblioteca do Exército Editora, 2003. Tomo 2. p. 359-414.

ELLMAN, Jesse; SAMP, Lisa; COLL, Gabriel. Assessing the third offset strategy: a report of the CSIS International Security Program. Washington: Center for Strategic and International Studies, 2017.

HAGEL, Chuck. Secretary of defense speech: Reagan national defense forum keynote. Simi Valley, California, 5 Nov. 2014. Disponível em: https://www.defense.gov/News/Speeches/Speech-View/Article/606635/. Acesso em: 29 out. 2020.

HEGEL, Georg. W. F. A. Princípios da filosofia do direito. Trad. Orlando Vitorino. São Paulo: Martins Fontes, 2009.

HUNTINGTON, Samuel P. The lonely superpower. Foreign Affairs, [s.l.], Mar./Apr. 1999. Disponível em: https://www.foreignaffairs.com/articles/unitedstates/1999-03-01/lonely-superpower. Acesso em: 31 out. 2020. 
PROENÇA JÚNIOR, Domício; DUARTE, Érico E. Projeção de poder e intervenção militar pelos Estados Unidos da América. Rev. Bras. Pol. Int, Brasília, v. 46, n. 1, p. 135-152, 2003.

KAPLAN, Robert D. A vingança da geografia: a construção do mundo geopolítico a partir da perspectiva geográfica. Tradução Cristiana de Assis Serra. Rio de Janeiro: Elsevier, 2013.

KEEGAN, John. Uma história da guerra. São Paulo: Companhia de Bolso, 2006.

KRAUTHAMMER, Charles. The unipolar moment. Foreign Affairs, [s.l.], $\vee 70$, n. 1. p. 23-33, 1991.

KRETCHIK, Walter E. U.S. army doctrine: from the American revolution to the War on Terror. Kansas: University Press of Kansas, 2011.

LOCHER III, James R.; NUNN, Sam. Victory on the potomac: the GoldwaterNichols act unifies the Pentagon. College Station: Texas A\&M University Press, 2002.

LOURENÇÃO, Humberto José; CORDEIRO, Luis Eduardo Pombo Celles. Força Militar dos EUA no pós-guerra fria: ganhando batalhas e perdendo guerras. Rev. Bras. Est. Def., Rio de Janeiro, v. 3, n. 2, p. 103-117, jul./dez. 2016.

OWENS, William A. The emerging U.S. system-of-systems. Strategic Forum, [Washington], n. 63, Feb. 1996. Disponível em:

https://web.archive.org/web/20100105160638/http://www.ndu.edu/inss/strforum /SF_63/forum63.html. Acesso em: 31 out. 2020.

PASSOS, Rodrigo Duarte Fernandes dos. Clausewitz e a política: uma leitura de 'Da Guerra'. 2006. 122 p. Tese (Doutorado em Ciência Política) - Faculdade de Filosofia, Letras e Ciências Humanas, Universidade de São Paulo, São Paulo, 2005.

PEDROSA, Fernando Velôzo G. A história militar tradicional e a "nova história militar”. In: SIMPÓSIO NACIONAL DE HISTÓRIA, 26., 2011, São Paulo. Anais [...]. São Paulo: Anpuh Nacional, 2011. Disponível em:

http://www.snh2011.anpuh.org/resources/anais/14/1300540601_ARQUIVO_ArtigoHistMilTradeNovaHist-Envio.pdf. Acesso em: 20 abr. 2019.

REIS, José C. A história entre a filosofia e a ciência. São Paulo: Editora Ática, 1996.

SANCHES, Marcos Guimarães. A guerra: problemas e desafios do campo da história militar brasileira. Revista Brasileira de História Militar, Rio de Janeiro, Ano I, n. 1, p. 6-16, abr. 2010. Disponível em: http://www.historiamilitar.com.br/wp-content/uploads/2017/08/RBHM-I-01.pdf. Acesso em: 05 maio 2019. 
SLOAN, Elinor. Modern military strategy. London: Routledge, 2012.

UNITED STATES OF AMERICA. Department of Defense (DoD). DoD dictionary of military and associated terms. [S.l.], Jan. 2021. Disponível em:

https://www.jcs.mil/Portals/36/Documents/Doctrine/pubs/dictionary.pdf. Acesso em: 24 mar. 2021.

UNITED STATES OF AMERICA. Department of Defense (DoD). Releases Fiscal Year 2017: president's budget proposal. [S.l.], 2016. Disponível em: https://dod.defense.gov/News/News-Releases/News-ReleaseView/Article/652687/department-of-defense-dod-releases-fiscal-year-2017presidents-budget-proposal/. Acesso: 30 out. 2020.

\section{UNITED STATES OF AMERICA. The White House. National Security Strategy of} the United States of America. [S.l.], Dec. 2017.

UNITED STATES OF AMERICA. Department of Defense (DoD). Joint operational access concept (JOAC): version 1.O. [S.l.], 17 Jan. 2012. Disponível em: https://archive.defense.gov/pubs/pdfs/JOAC_Jan\%202012_Signed.pdf. Acesso: 30 out. 2020.

UNITED STATES OF AMERICA. Department of State. The global war on terrorism: the first 100 days. [S.l.]: Archive, White House Counterterrorism Reports, 2001. Disponível em: https://2001-2009.state.gov/s/ct/rls/wh/6947.htm. Acesso em: 28 abr. 2021.

UNITED STATES OF AMERICA. Department of the Army. Marine Corps Combat Development Command. Field manual n. 3-24 / fleet marine force manual n. 324. Washington, 2006. Disponível em: DChttps://fas.org/irp/doddir/army/fm324fd.pdf. Acesso em: 31 out. 2020.

VISACRO, Alessandro. Guerra irregular: terrorismo, guerrilha e movimentos de resistência ao longo da História. São Paulo: Contexto. 2009.

WINTER, Jay; PROST, Antoine. Penser la Grande Guerre: un essai d'historiographie. Paris: Éditions Du Seuil, 2004.

Universidade do Estado de Santa Catarina - UDESC

Programa de Pós-Graduação em História - PPGH

Revista Tempo e Argumento Volume 13 - Número 32 - Ano 2021 tempoeargumento@gmail.com 